\title{
PRODUÇÃO DE MATÉRIA SECA EM PASTAGEM DE TIFTON 85 IRRIGADA, COM DIFERENTES DOSES DE DEJETO LÍQUIDO DE SUINO ${ }^{1}$
}

\section{LUÍS C. D. DRUMOND², JOSÉ R. ZANINI ${ }^{3}$, ADILSON DE P. A. AGUIAR ${ }^{4}$, GUILHERME P. RODRIGUES ${ }^{5}$, ANDRÉ L. T. FERNANDES ${ }^{6}$}

\begin{abstract}
RESUMO: O dejeto líquido de suíno (DLS) pode constituir-se em excelente fonte de adubação em pastagem, com aplicação por aspersão, desde que seja assegurada a proteção do meio ambiente. Apesar de seu comprovado potencial para uso em sequeiro, pouco se conhece sobre o comportamento da cultivar Tifton 85 em sistemas sob irrigação e sob aplicação de DLS. Para determinar a produção de matéria seca pré-pastejo de Tifton 85 com DLS, foi conduzido um experimento na Fazenda-Escola da Universidade de Uberaba, irrigado por aspersão em malha, com aplicação de 0; 50; 100 e $200 \mathrm{~m}^{3} \mathrm{ha}^{-1}$ ano $^{-1}$ de DLS. Houve efeito significativo das doses de DLS em relação à produção de matéria seca pré-pastejo, ocorrendo acréscimos de produção com o aumento das doses. O fornecimento de $200 \mathrm{~m}^{3} \mathrm{ha}^{-1} \mathrm{ano}^{-1}$ de DLS possibilitou produção de $5.928 \mathrm{~kg}$ de matéria seca (MS) da forrageira por ciclo de 28 dias.
\end{abstract}

PALAVRAS-CHAVE: irrigação de pastagem, água residuária, aspersão em malha.

\section{DRY MATTER PRODUCTION OF IRRIGATED TIFTON 85 FORAGE, WITH DIFFERENT LIQUID SWINE DEJECTION RATES}

\begin{abstract}
Liquid swine dejection (LSD) can constitute excellent source of fertilization in pasture, with sprinkler irrigation system, provided the conditions that assure the protection of the environment. Although with proved potential for growth without irrigation, for the Cynodon $s p$ cultivar Tifton 85 there is little information on its behavior and production in systems under irrigation and with LSD. In order to determine the production of dry matter in irrigated and with LSD fertirrigation, an experiment was carried out in the Farm-School of the University of Uberaba - MG, Brazil, with net-sprinkler irrigation system, applying 0, 50, 100 and $200 \mathrm{~m}^{3} \mathrm{ha}^{-1}$ year ${ }^{-1}$ of LSD. There was significant effect among the doses of LSD in the production of dry matter, occurring additions of production with the increasing the doses. The supply of $200 \mathrm{~m}^{3} \mathrm{ha}^{-1} \mathrm{year}^{-1}$ of LSD made possible the production of $5,928 \mathrm{~kg}$ of the forage dry matter for the cycle of 28 days.
\end{abstract}

KEYWORDS: pasture irrigation, wastewater, net-sprinkler irrigation system.

\section{INTRODUÇÃO}

A irrigação e a fertirrigação em pastagem são técnicas cujas aplicações vêm crescendo no Brasil, possibilitando obter forrageiras de melhor valor nutricional, além de favorecer o manejo racional do sistema de produção animal.

O sistema de irrigação por aspersão em malha está sendo bastante utilizado em pastagem, cana forrageira e capineiras, por se tratar de sistema de baixo custo (DRUMOND \& FERNANDES, 2001). Apesar disso, poucas são as pesquisas existentes sobre esse sistema no Brasil.

\footnotetext{
${ }^{1}$ Extraído da tese de doutorado do primeiro autor.

${ }^{2}$ Eng ${ }^{\mathrm{o}}$ Agrônomo, Prof. Doutor, FAZU e UNIUBE, Uberaba - MG, Fone: (0XX34) 3318.4188, ldrumond@ @azu.br

${ }^{3}$ Eng ${ }^{\circ}$ Agrônomo, Prof. Doutor, Departamento de Engenharia Rural, UNESP, Jaboticabal - SP.

${ }^{4}$ Zootecnista, Prof.essor, FAZU/UNIUBE, Uberaba - MG.

${ }^{5}$ Eng $^{\mathrm{o}}$ de Alimentos, Prof. M.Sc., UNIUBE, Uberaba - MG.

${ }^{6}$ Eng $^{\circ}$ Agrônomo, Prof. Doutor, UNIUBE, Uberaba - MG.

Recebido pelo Conselho Editorial em: 9-12-2005
}

Aprovado pelo Conselho Editorial em: 16-10-2006 
Tem sido crescente o interesse de técnicos e produtores sobre novas espécies forrageiras de alto potencial de produção para serem implantadas em sistemas intensivos de pastagem sob irrigação (AGUIAR \& DRUMOND, 2002). Porém, são poucas as informações sobre crescimento e produção da cultivar Tifton 85 , sob sistemas irrigados e sob aplicação de dejetos de suínos.

Segundo DOVRAT (1993), em muitos países, técnicos e produtores inicialmente usaram a irrigação na tentativa de solucionar o problema da estacionalidade de produção das pastagens, que é determinada pelo déficit dos fatores temperatura, luminosidade e água. A irrigação da pastagem poderia reduzir custos de produção e tempo de trabalho para alimentar o rebanho, comparada a outras alternativas de suplementação no outono-inverno, tais como a silagem e o feno. Isso ocorre pela utilização de menor área, uso de água de baixa qualidade e possibilidade de prolongar o período de pastejo durante a estação seca.

ROLIM (1994) cita que, em trabalhos realizados entre 1966 e 1978, pesquisadores obtiveram aumento de produção de forragem que variou entre 20 e $70 \%$ nas áreas irrigadas, durante um período de 150 dias, nas estações de outono-inverno da região do Brasil Central. Ele concluiu que esses aumentos não foram suficientes para o equilíbrio das produções de verão e inverno.

Segundo CORSI (1993), o número de cabeças ha ${ }^{-1}$ variou de 1,5 com adubação e irrigação no outono-inverno, enquanto no verão foi possível obter lotação de 4,0 a 7,5 cabeças ha ${ }^{-1}$, apenas melhorando o manejo dos animais e com adubação, na região de Piracicaba - SP. Segundo o autor, esses dados desencorajaram a aplicação de irrigação em algumas regiões, principalmente onde a média de temperatura de inverno era de $15^{\circ} \mathrm{C}$.

Segundo AGUIAR \& DRUMOND (2002), em regiões onde a temperatura não é fator limitante, a irrigação pode ser uma alternativa para a produção intensiva de carne e leite em pequenas áreas, sendo possível reduzir custos de produção e de mão-de-obra.

ALVIM et al. (1996), avaliando capim "coast-cross" irrigado na seca, com lâmina de 30 a $35 \mathrm{~mm}$ a cada 15 dias e sem adubação nitrogenada, conseguiram, no inverno, $28 \%$ da produção da primavera-verão. Com irrigação e adubação nitrogenada $\left(250 ; 500\right.$ e $750 \mathrm{~kg} \mathrm{de} \mathrm{N} \mathrm{ha}^{-1}$ ano $\left.^{-1}\right)$, obtiveram de 38 a $43 \%$.

Segundo KONZEN (2002), em Patos de Minas - MG, foram testadas doses de até $180 \mathrm{~m}^{3} \mathrm{ha}^{-1}$, de DLS no ciclo do milho, alcançando $7.000 \mathrm{~kg} \mathrm{ha}^{-1}$, sendo observado baixo efeito residual. No terceiro ano após a aplicação dessa dose, a produção igualou-se à da testemunha. $\mathrm{O}$ autor cita que em pastagem de tanzânia e mombaça, em Brasilândia - MS, foram obtidas produções de matéria seca da ordem de $8.000 \mathrm{~kg} \mathrm{ha}^{-1} \mathrm{mês}^{-1}$, utilizando-se de fertirrigação com DLS, em dose de $180 \mathrm{~m}^{3} \mathrm{ha}^{-1}$.

Segundo AGUIAR \& DRUMOND (2002), a aplicação de dejeto de suíno para recuperação de pastagens merece atenção, pois existem cerca de 100 milhões de hectares de pastagens no Brasil que necessitam de recuperação. Os primeiros resultados de pesquisa sobre este assunto foram desenvolvidos pela Universidade Federal de Santa Maria - RS, realizando aplicação de dejeto de suíno durante 1998 e 1999. Com aplicação de dejeto em dose de $40 \mathrm{~m}^{3} \mathrm{ha}^{-1}$, os pesquisadores obtiveram aumento de 3,07 vezes na produção de matéria seca.

Aplicando dejeto de suíno em pastagem de braquiarão, em Rio Verde - GO, com dose de 180 $\mathrm{m}^{3} \mathrm{ha}^{-1}$, foi possível dobrar a capacidade de lotação (KONZEN, 2002). Também, segundo esse pesquisador, em pastagem de capim-tanzânia e mombaça, em Brasilândia - MS, a aplicação de DLS em fertirrigação através de pivô central possibilitou produções de $8.000 \mathrm{~kg} \mathrm{de} \mathrm{MS} \mathrm{ha}^{-1}$ mês $^{-1}$, atingindo lotações de 8,0 unidades animais (450 kg de peso vivo) por hectare, com média de ganho de $0,8 \mathrm{~kg}_{\text {animal }}{ }^{-1} \mathrm{dia}^{-1}$.

Em muitas fazendas no Brasil, existe considerável volume de água residuária que poderia ser utilizada para adubação em várias culturas. Os custos com transporte e mão-de-obra para aplicação desses dejetos têm levado a se buscarem alternativas mais econômicas, como a aplicação via sistema de irrigação, pois, dependendo de sua origem, o resíduo animal pode conter 60 a $98 \%$ de 
líquido. Nos Estados Unidos, o uso da irrigação para aplicação de estercos líquidos apresenta crescimento desde o início da década de 1970.

Este trabalho foi desenvolvido com o objetivo de avaliar a produção da matéria seca prépastejo do Tifton 85, recebendo aplicação de água e três doses de dejeto líquido de suíno, com sistema de irrigação por aspersão em malha.

\section{MATERIAL E MÉTODOS}

A pesquisa foi conduzida na Fazenda Alexandre Barbosa, da Universidade de Uberaba MG, localizada a $19^{\circ} 45^{\prime}$ de latitude sul e a $47^{\circ} 55^{\prime}$ de longitude oeste, com altitude entre 820 e 880 m. O experimento foi conduzido de março a agosto de 2000, numa área de 4,0 hectares, topografia suave-ondulada, cultivada com capim Cynodon sp cv Tifton 85.

\section{Sistema de irrigação}

Instalou-se um sistema de aspersão, utilizando-se dos aspersores: a) Naan 5035, bocais 5,0 x $2,5 \mathrm{~mm}$, pressão de serviço $280 \mathrm{kPa}$, vazão nominal de $1.875 \mathrm{~L} \mathrm{~h}^{-1}$ e ângulo de inclinação do jato igual a $23^{\circ}$, denominado aspersor A; b) Netafim, modelo $\mathrm{N} 95$, bocais 5,0 x 2,2 mm, pressão de serviço $280 \mathrm{kPa}$, vazão nominal de $1.675 \mathrm{~L} \mathrm{~h}^{-1}$ e ângulo de inclinação do jato igual a $23^{\circ}$, denominado aspersor B. Esses dois modelos de aspersores foram adotados por serem comumente utilizados na prática, porém, por possuírem diferentes distribuições de água, houve interesse em se verificar a influência dos mesmos na produção de matéria seca.

O sistema utilizado é semiportátil e de baixo custo, constituído de linhas principais, de derivação, e laterais fixas e enterradas, com mudança apenas dos aspersores, constituindo uma rede em malha, comumente denominada de aspersão em malha (DRUMOND \& FERNANDES, 2001). As linhas laterais eram de PVC soldável, espaçadas de 18 metros, interligadas, pressão nominal de 60 mca (PN 60) e diâmetro de $25 \mathrm{~mm}$. Os aspersores foram conectados a essas linhas com espaçamento de $18 \mathrm{~m}$, com $60 \mathrm{~cm}$ de altura em relação ao solo.

A linha de derivação era de PVC soldável, de $50 \mathrm{~mm}$, PN 80. A linha principal era também de PVC soldável, de $75 \mathrm{~mm}$ e PN 80. As linhas laterais foram interligadas em anéis, e a estabilização hidráulica foi realizada utilizando o processo Hardy Cross (PORTO, 2000). Com isso, consegue-se operar com baixos diâmetros nas linhas laterais, com baixa potência do conjunto motobomba e, conseqüentemente, com economia de energia.

No experimento, as aplicações do dejeto líquido e água foram realizadas procurando-se elevar a umidade do solo à capacidade de campo, utilizando-se de um fator de disponibilidade de água igual a 40\%, baseando-se no balanço hídrico climatológico, com dados de clima obtidos em estação meteorológica automatizada Micrometos 300, descrita por FERNANDES (2001). A retenção de água no solo foi determinada em laboratório, utilizando-se de amostras indeformadas, pelo método da Câmara de Richards. As lâminas aplicadas foram calculadas com base na evapotranspiração acumulada, estimada pela equação de Penman-Monteith, com turno de rega variável.

\section{Dejeto líquido de suíno (DLS)}

A água residuária utilizada foi obtida de uma granja de sistema de engorda, localizada próxima à área experimental. Os dejetos foram canalizados das baias, para uma caixa principal de separação. A função dessa caixa era separar o líquido do sólido e direcioná-lo para uma caixa secundária que, por sua vez, descarregava nas lagoas de estabilização. Após completar o período de tratamento nas lagoas, o DLS foi conduzido a uma caixa de recepção com $4,6 \mathrm{~m}^{3}$. O esquema do processo de separação do dejeto líquido até a lagoa de estabilização está apresentado na Figura 1.

Durante as fertirrigações, procurou-se manter constante a taxa de injeção de DLS no sistema de irrigação, controlando-se o volume aplicado, na caixa de recepção, já que suas dimensões eram conhecidas. Uma tubulação de PVC ligava a caixa de recepção de DLS à sucção da motobomba, e 
a vazão do DLS que deveria ser aplicado, era controlada utilizando-se de registros de gaveta, mantendo-se a aplicação durante duas horas. Durante a aplicação de água, o registro que permitia a sucção de DLS, era mantido fechado.

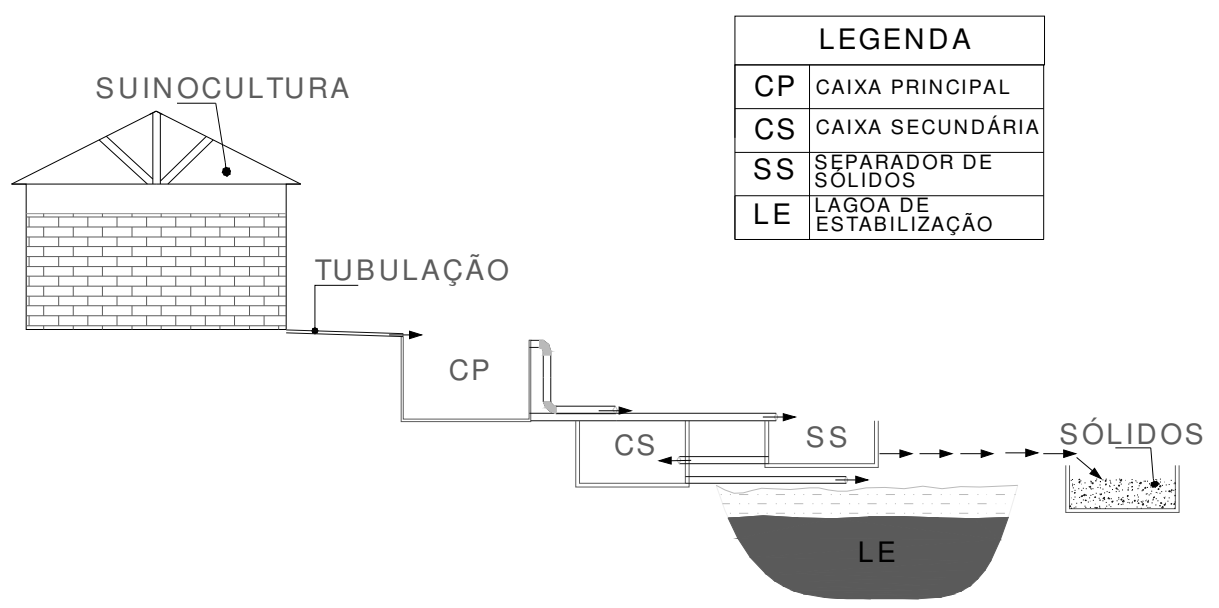

FIGURA 1. Esquema representando o processo de tratamento do dejeto.

As análises químicas do DLS e da água foram feitas em 02 de março, 28 de abril e 20 de junho de 2000, e os valores médios dos resultados estão apresentados na Tabela 1.

TABELA 1. Valores médios obtidos nas análises químicas do DLS e da água.

\begin{tabular}{|c|c|c|c|c|c|c|c|c|c|c|c|c|c|c|}
\hline \multirow[b]{2}{*}{ Elemento } & $\mathrm{N}$ & $\mathrm{P}$ & $\mathrm{K}$ & $\mathrm{Ca}$ & $\mathrm{S}$ & $\mathrm{Mg}$ & $\mathrm{Zn}$ & $\mathrm{Cu}$ & $\mathrm{B}$ & $\mathrm{Fe}$ & $\mathrm{Mn}$ & $\mathrm{Na}$ & $\mathrm{MO}$ & Dens \\
\hline & \multicolumn{2}{|c|}{$----g^{-1}---$} & & & & & $-m g$ & $L^{-1}-$ & - & - & - & ------ & $\%$ & $\mathrm{~kg} \mathrm{~L}^{-1}$ \\
\hline Água & - & - & 0,15 & 0,18 & - & 0,03 & 0,6 & - & - & 2,0 & - & 0,3 & - & 1,01 \\
\hline DLS & 1,3 & 0,18 & 600,0 & 100,0 & 50,0 & 50,0 & 6,0 & 4,0 & 6,0 & 25,0 & 5,0 & 142,0 & 0,35 & 0,97 \\
\hline
\end{tabular}

MO: matéria orgânica; Dens: densidade da amostra.

\section{Aplicação de água e dejeto líquido de suíno}

Após o enchimento da lagoa de estabilização com o DLS, o material era deixado em repouso até completar o período de tratamento, que durava cerca de 60 dias. As doses estabelecidas de DLS, foram parceladas em 24 vezes, aplicadas em 6 ciclos (Tabela 2), com 4 repetições por ciclo. Tendo-se estabelecido $200 \mathrm{~m}^{3} \mathrm{ha}^{-1}$ como a maior dose, para os demais tratamentos, após a aplicação de DLS o sistema de irrigação era mantido aplicando somente água, até completar $200 \mathrm{~m}^{3} \mathrm{ha}^{-1}$.

Além das aplicações de DLS, eram realizadas irrigações para elevar a umidade do solo em torno da capacidade de campo. Nos três primeiros ciclos, a umidade do solo foi dependente das irrigações e das chuvas, porém, nos três últimos ciclos, a necessidade de água calculada pelo balanço hídrico foi suprida apenas com irrigações.

TABELA 2. Datas dos ciclos de pastejo, totais de precipitação e médias de temperatura durante o experimento.

\begin{tabular}{ccccccc}
\hline \multirow{2}{*}{ Ciclos } & \multirow{2}{*}{ Início } & \multirow{2}{*}{ Final } & \multirow{2}{*}{\begin{tabular}{c} 
Precipitação \\
\cline { 5 - 6 }
\end{tabular}} & & $(\mathrm{mm})$ & \multicolumn{3}{c}{ Temperatura $\left({ }^{\circ} \mathrm{C}\right)$} \\
\hline Primeiro & $8-3-2000$ & $4-4-2000$ & 233,5 & 23,1 & 18,2 & 29,2 \\
Segundo & $5-4-2000$ & $2-5-2000$ & 40,5 & 21,7 & 17,1 & 29,1 \\
Terceiro & $3-5-2000$ & $30-5-2000$ & 5,5 & 20,4 & 15,2 & 27,6 \\
Quarto & $31-5-2000$ & $27-6-2000$ & 0,0 & 19,2 & 13,9 & 26,9 \\
Quinto & $28-6-2000$ & $25-7-2000$ & 0,0 & 18,6 & 13,3 & 26,3 \\
Sexto & $26-7-2000$ & $22-8-2000$ & 0,0 & 20,8 & 16,8 & 28,9 \\
\hline
\end{tabular}




\section{Determinação da produção da forragem}

Antes do primeiro ciclo de coleta de dados, foi realizado um corte para a uniformização da forrageira, a $15 \mathrm{~cm}$ de altura do solo, e, logo após, foi realizada uma adubação química (nitrogênio: $100 \mathrm{~kg} \mathrm{ha}^{-1}$; fósforo $\left(\mathrm{P}_{2} \mathrm{O}_{5}\right): 28 \mathrm{~kg} \mathrm{ha}^{-1}$; potássio $\left(\mathrm{K}_{2} \mathrm{O}\right): 72 \mathrm{~kg} \mathrm{ha}^{-1}$, e enxofre: $\left.25 \mathrm{~kg} \mathrm{ha}^{-1}\right)$.

Para a avaliação da massa de forragem, foi utilizada uma moldura de $1 \mathrm{~m} x 1 \mathrm{~m}$, que era jogada aleatoriamente quatro vezes na parcela. A forrageira foi cortada rente ao solo, e a massa coletada foi pesada no campo, para se determinar a massa fresca. Desse material fresco, foram retiradas amostras (aproximadamente $0,5 \mathrm{~kg}$ ), para secagem em estufa a $105^{\circ} \mathrm{C}$, por 24 horas, obtendo-se a massa seca.

\section{Delineamento experimental e tratamentos utilizados}

Foi adotado o delineamento experimental em parcelas subdivididas, constituindo um fatorial $2 \times 4$, com quatro repetições. As parcelas representaram os dois aspersores, e as subparcelas, as doses de DLS $\left(0 ; 50 ; 100\right.$ e $\left.200 \mathrm{~m}^{3} \mathrm{ha}^{-1} \mathrm{ano}^{-1}\right)$. As doses foram parceladas em quatro aplicações semanais, dentro dos ciclos. Os tratamentos avaliados foram:

Tratamento 1 - Aplicação de água com aspersor A (T1);

Tratamento 2 - Aplicação de $50 \mathrm{~m}^{3} \mathrm{ha}^{-1} \mathrm{ano}^{-1}$ de DLS com aspersor A (T2);

Tratamento 3 - Aplicação de $100 \mathrm{~m}^{3} \mathrm{ha}^{-1}$ ano $^{-1}$ de DLS com aspersor A (T3);

Tratamento 4 - Aplicação de $200 \mathrm{~m}^{3} \mathrm{ha}^{-1} \mathrm{ano}^{-1}$ de DLS com aspersor A (T4);

Tratamento 5 - Aplicação de água com aspersor B (T5) ;

Tratamento 6 - Aplicação de $50 \mathrm{~m}^{3} \mathrm{ha}^{-1} \mathrm{ano}^{-1}$ de DLS com aspersor B (T6);

Tratamento 7 - Aplicação de $100 \mathrm{~m}^{3} \mathrm{ha}^{-1} \mathrm{ano}^{-1}$ de DLS com aspersor B (T7), e

Tratamento 8 - Aplicação de $200 \mathrm{~m}^{3} \mathrm{ha}^{-1}$ ano $^{-1}$ de DLS com aspersor B (T8).

\section{RESULTADOS E DISCUSSÃO}

Pela Figura 2, pode-se verificar que ocorreu aumento de cerca de duas vezes na produção de MS, no tratamento com $200 \mathrm{~m}^{3}$ ha $^{-1}$ ano $^{-1}$ de DLS, em relação ao tratamento onde foi aplicada somente água.

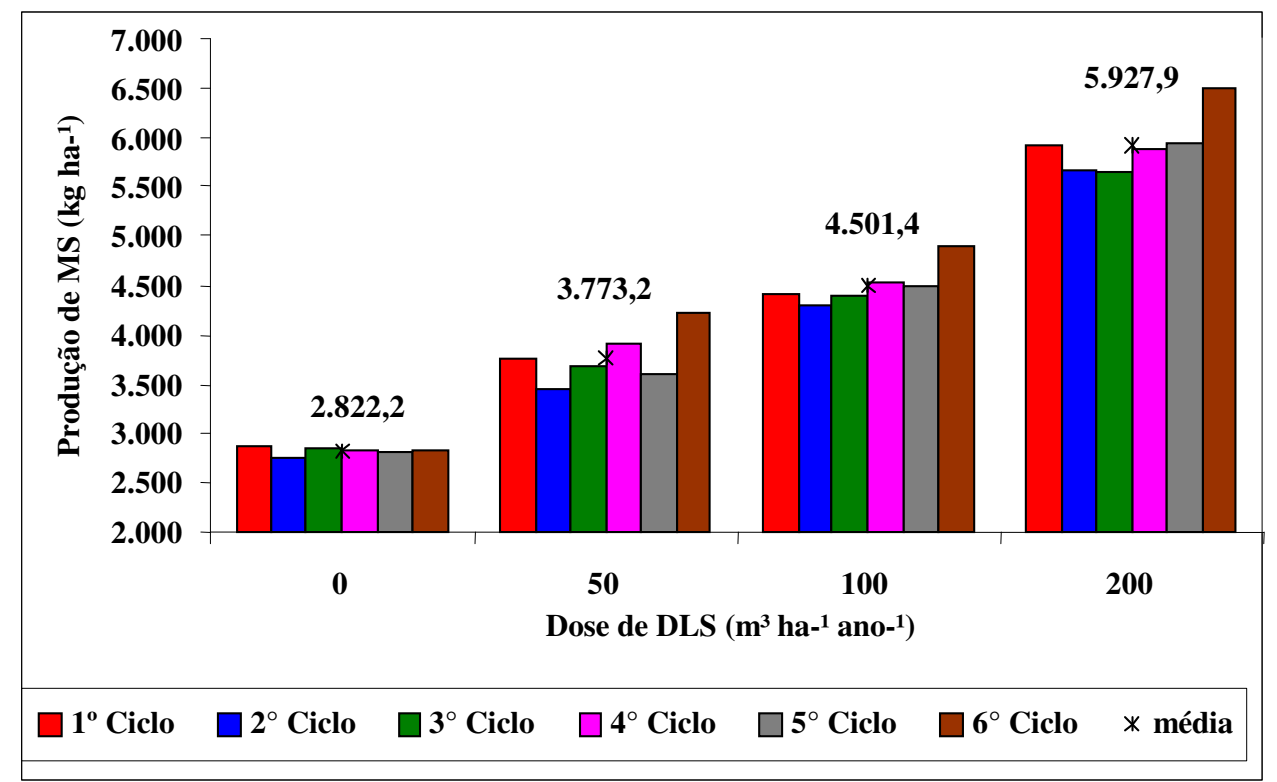

FIGURA 2. Produção de matéria seca pré-pastejo para as doses aplicadas de DLS. 
Resultado semelhante de aumento na produção de MS foi obtido por ROSA et al. (2002), com aplicação de dejeto de suíno em braquiarão (Brachiaria brizantha cv. Marandu), com doses de 100; 150 e $200 \mathrm{~m}^{3} \mathrm{ha}^{-1} \mathrm{ano}^{-1}$, em Goiânia - GO. No experimento desses autores, a aplicação de 200 $\mathrm{m}^{3} \mathrm{ha}^{-1}$ ano $^{-1}$ proporcionou $8.518 \mathrm{~kg} \mathrm{ha}^{-1}$ de MS por ciclo de 35 dias. Essa produção foi superior à de $8.049 \mathrm{~kg} \mathrm{ha}^{-1}$ de MS por ciclo, obtida com a aplicação de $3,5 \mathrm{~kg} \mathrm{ha}^{-1}$ de $\mathrm{P}_{2} \mathrm{O}_{5} ; 18 \mathrm{~kg} \mathrm{ha}^{-1}$ de $\mathrm{K}_{2} \mathrm{O}$; $160 \mathrm{~kg} \mathrm{ha}^{-1}$ de $\mathrm{N}$ e micronutrientes, aplicados por tonelada de MS de forragem estimada a ser colhida por hectare. Com relação à análise bromatológica, não houve diferenças significativas $(\mathrm{P}<0,05)$ entre os teores de fibra digestível em detergente neutro (FDN), fibra digestível em detergente ácido (FDA) e hemicelulose, para a adubação química e com dejetos.

Os resultados de produção de matéria seca deste experimento estão em conformidade com os obtidos por BARNABÉ (2001), que, trabalhando com braquiarão, obteve aumento de 1,56 vez na produção de MS, em relação à testemunha, aplicando $150 \mathrm{~m}^{3} \mathrm{ha}^{-1}$ ano $^{-1}$ de dejeto de suíno. Estão de acordo também com AZEVÊDO (1991), que aplicou 0; 5; 10; 15 e $20 \mathrm{t} \mathrm{ha}^{-1}$ de dejetos de suínos em capim-gordura (Melinis minutiflora Beauv.) e verificou que a produção de MS aumentou de forma quadrática com as doses utilizadas, atingindo um máximo de MS de $9.365 \mathrm{~kg} \mathrm{ha}{ }^{-1}$, representando aumento de cerca de $1,20 \mathrm{vez}$, em relação à testemunha.

Existe consenso de os dejetos de suínos apresentam poder poluente, especialmente para os recursos hídricos, por causa de sua alta demanda bioquímica de oxigênio (DBO). Porém, as pesquisas com aplicação de dejetos como fertilizantes têm apresentado resultados evidenciando que podem e devem ser utilizados como insumo útil e econômico na produção agropecuária.

Alguns experimentos têm sido desenvolvidos mostrando o efeito da aplicação de DLS na produção de grãos. Segundo KONZEN (2002), a dose a ser aplicada de DLS deve seguir o princípio de exportação de nutrientes para a produção das culturas. $\mathrm{O}$ autor cita que, em pesquisa realizada em Patos de Minas - MG, foram obtidas produtividades crescentes, variando de 5.179 a

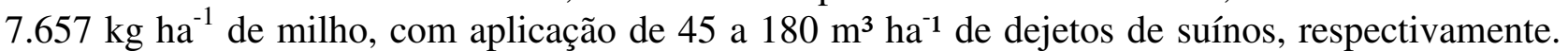
Não ocorreu efeito da aplicação de nitrogênio em cobertura, levando à conclusão de que as quantidades de dejetos aplicadas supriram as necessidades de nitrogênio para produções de 7.000 a $8.000 \mathrm{~kg} \mathrm{ha}^{-1} \mathrm{de}$ milho. A pesquisa demonstrou, ainda, que os dejetos de suínos apresentam baixo efeito residual, mesmo com doses de $180 \mathrm{~m}^{3} \mathrm{ha}^{-1}$.

Em pesquisa realizada em Rio Verde - GO, em sistema de plantio direto, KONZEN (2002) cita que foi obtida produtividade de $8.440 \mathrm{~kg} \mathrm{ha}^{-1}$ de milho, com aplicação de $100 \mathrm{~m}^{3} \mathrm{ha}^{-1}$ de dejetos de suínos; para soja, aplicando-se $75 \mathrm{~m}^{3} \mathrm{ha}^{-1}$, foi obtida produtividade de $3.520 \mathrm{~kg} \mathrm{ha}^{-1}$.

Analisando os valores obtidos na análise de variância para a produção de matéria seca (Tabela 4), verifica-se que não houve efeito significativo do fator modelo dos aspersores, a 5\% de probabilidade. Embora os modelos empregados neste experimento sejam freqüentemente utilizados na prática, poderia haver diferença de distribuição de DLS pelos mesmos, como, por exemplo, por problemas de entupimento.

TABELA 4. Resultado da análise de variância, para a produção de matéria seca do Tifton 85.

\begin{tabular}{cccccccc}
\hline \multirow{2}{*}{ Fatores } & \multirow{2}{*}{ GL } & $1^{-}$Ciclo & $2^{-}$Ciclo & $3^{-}$Ciclo & $4^{-0}$ Ciclo & $5^{-0}$ Ciclo & $6^{-0}$ Ciclo \\
\cline { 2 - 7 } & $\mathrm{F}$ & $\mathrm{F}$ & $\mathrm{F}$ & $\mathrm{F}$ & $\mathrm{F}$ & $\mathrm{F}$ \\
\hline $\begin{array}{c}\text { Modelo dos } \\
\text { Aspersores }\end{array}$ & 1 & $1,10^{\mathrm{NS}}$ & $2,76^{\mathrm{NS}}$ & $2,39^{\mathrm{NS}}$ & $0,25^{\mathrm{NS}}$ & $1,51^{\mathrm{NS}}$ & $0,05^{\mathrm{NS}}$ \\
\hline Dose de DLS & 3 & $225,73^{*}$ & $529,89^{*}$ & $435,71^{*}$ & $488,52^{*}$ & $651,41^{*}$ & $1.659,86^{*}$ \\
\hline Interação & 3 & $0,18^{\mathrm{NS}}$ & $0,66^{\mathrm{NS}}$ & $1,32^{\mathrm{NS}}$ & $0,23^{\mathrm{NS}}$ & $0,92^{\mathrm{NS}}$ & $0,61^{\mathrm{NS}}$ \\
\hline
\end{tabular}

* significativo a 5\% de probabilidade;. NS: não-significativo estatisticamente.

Na Figura 3, são apresentadas as produções de MS pré-pastejo, em função das doses de DLS, e a equação gerada para os valores médios dos seis ciclos e dos dois aspersores. 


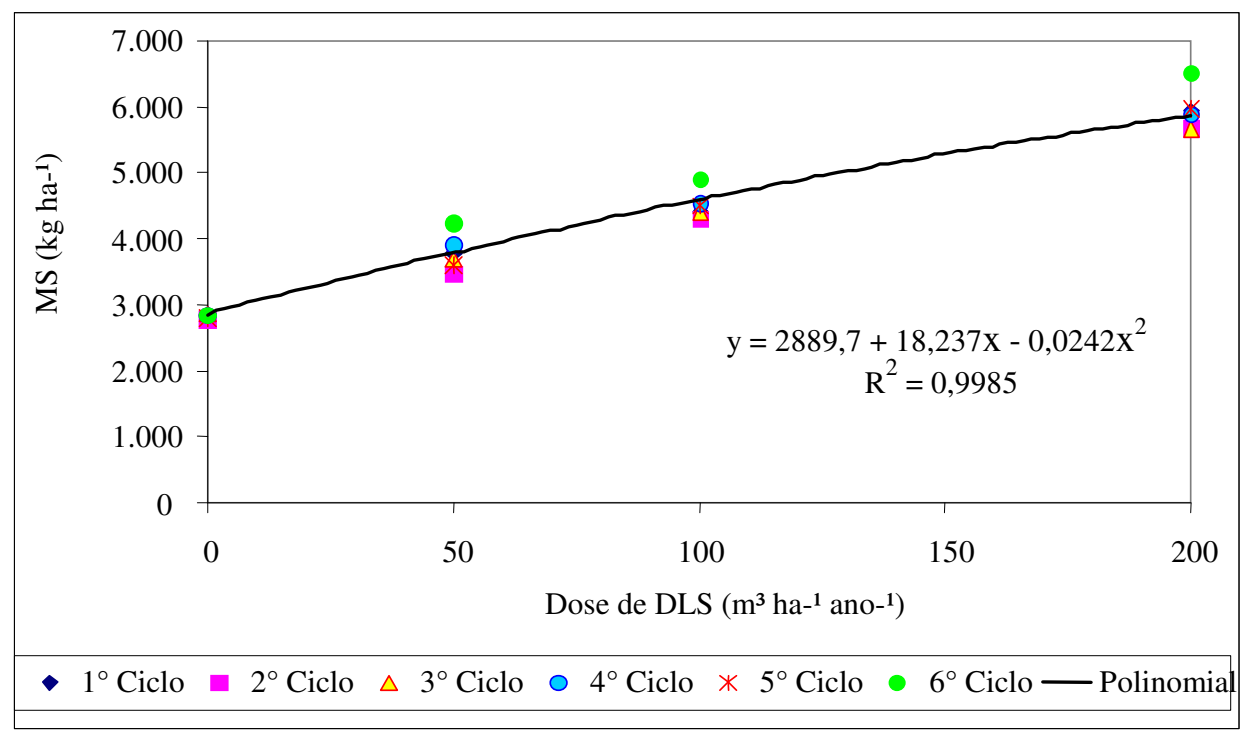

FIGURA 3. Produção de matéria seca pré-pastejo em função das doses aplicadas de DLS.

O coeficiente de determinação $\mathrm{R}^{2}$ foi de 0,99 , indicando boa correlação dos valores da produção da MS com as doses de DLS aplicadas. Em relação à equação obtida (Figura 3), derivando-se a mesma, é encontrado o ponto de máximo; desse modo, a produção máxima estimada de matéria seca seria de $6.325,5 \mathrm{~kg} \mathrm{ha}^{-1}$, obtida com a aplicação de $378,4 \mathrm{~m}^{3} \mathrm{ha}^{-1}$ ano $^{-1}$ de DLS. Esses valores permitem admitir que a dose máxima utilizada no presente experimento pode ser aumentada; porém, para isso, há necessidade de estudos sobre impactos ambientais.

Para o fator dose de DLS, ocorreu efeito significativo a 5\% de probabilidade, em todos os ciclos, indicando que a dose aplicada teve interferência na produção de matéria seca pré-pastejo, ocorrendo aumento crescente na produção de MS com o aumento da dose de DLS. Isso significa que existe, pelo menos, um contraste entre as médias dos níveis desse fator, que é estatisticamente diferente de zero, a 5\% de probabilidade. Resultados semelhantes foram obtidos por AZEVÊDO (1991), BARNABÉ (2001), ROSA et al. (2002) e KONZEN (2002).

\section{CONCLUSÕES}

Houve efeito significativo da dose de dejeto líquido de suíno em relação à produção de matéria seca pré-pastejo, ocorrendo acréscimos de produção com o aumento da dose.

O fornecimento de $200 \mathrm{~m}^{3} \mathrm{ha}^{-1}$ ano $^{-1}$ de dejeto líquido de suíno possibilitou produção de $5.928 \mathrm{~kg}$ de matéria seca por ciclo de 28 dias, correspondendo acerca de duas vezes a produção de Tifton 85 do tratamento que recebeu somente água.

Os dois modelos de aspersores utilizados não apresentaram diferença significativa para a produção de matéria seca pré-pastejo.

\section{REFERÊNCIAS}

AGUIAR, A.P.A.; DRUMOND, L.C.D. Pastagens Irrigadas. In: CURSO DE ESPECIALIZAÇÃO EM MANEJO DA PASTAGEM, 2002, Uberaba: FAZU, 86 p.

ALVIM, M.J.; RESENDE, H.; BOTREL, M. A. Efeito da freqüência de cortes e do nível de nitrogênio sobre a produção e qualidade da matéria seca do "coast-cross" In: WORKSHOP SOBRE O POTENCIAL FORRAGEIRO DO GÊNERO Cynodon, 1996, Juiz de Fora. Anais... Juiz de Fora: EMBRAPA-CNPGL, 1996. p.45-56.

AZEVÊDO, M.L.A. Utilização de estercos de suínos “in natura” em pastagem de capim gordura (Mellinis minutiflora Beauv.). 1991. 74 f. Dissertação (Mestrado em Solos e Nutrição de Plantas) Universidade Federal de Viçosa, Viçosa, 1991. 
BARNABÉ, M.C. Produção e composição bromatológica da Brachiaria brizantha Stapf cv Marandu adubada com dejetos líquidos de suínos. 2001. 93 f. Dissertação (Mestrado em Produção Animal) - Universidade Federal de Goiás, Goiânia, 2001.

CORSI, M. Manejo do capim-elefante sob pastejo. In: SIMPÓSIO SOBRE MANEJO DE PASTAGEM, 10., 1993, Piracicaba. Anais... Piracicaba: FEALQ, 1993. v.1, p.143-69.

DOVRAT, A. Developments in Crop Science 24: Irrigated forage production. Amsterdam: Elsevier, 1993. 257 p.

DRUMOND, L.C.D.; FERNANDES, A.L.T. Irrigação por aspersão em malha. Uberaba: Ed. Universidade de Uberaba, 2001. 84 p.

FERNANDES, A.L.T. Fertirrigação na cultura do melão em ambiente protegido, utilizando fertilizantes organominerais e químicos. 2001. 94 f. Tese (Doutorado em Engenharia Agrícola) Universidade Estadual de Campinas, Campinas, 2001.

KONZEN, E.A. Aproveitamento do adubo líquido da suinocultura na produção agropecuária. In: CONGRESSO NACIONAL DE IRRIGAÇÃO E DRENAGEM, 12., 2002, Uberlândia. Anais... Uberlândia: ABID, 2002. 4p.

PORTO, R.M. Hidráulica básica. 2.ed. São Carlos: EESC Editora, 2000. 519 p.

ROSA, B.; BARNABÉ, F.H.G.A.; SILVA, L.T. Utilização de dejetos líquidos de suínos como fonte de NPK para o capim braquiarão (Brachiaria brizantha cv. Marandu). In: REUNIÃO ANUAL DA SOCIEDADE BRASILEIRA DE ZOOTECNIA, 39., 2002, Recife. Anais... Recife: UFRPE, 2002. 1 CD-ROM.

ROLIM, F.A. Estacionalidade de produção de forrageiras. In: PEIXOTO, A.M.; MOURA, J.C.; FARIA, V.P. (Ed.). Pastagens: fundamentos da exploração racional. Piracicaba: FEALQ, 1994. p.533-66. 